\title{
ESTUDO DO EFEITO DA COMPOSIÇÃO QUÍMICA E DOS PARÂMETROS DE LINGOTAMENTO NA OCORRÊNCIA DE TRINCAS EM BARRAS LAMINADAS*
}

Aline Kemp ${ }^{1}$

\begin{abstract}
Resumo
O objetivo deste trabalho é estudar o efeito da composição química e dos parâmetros de lingotamento convencional na ocorrência de trincas superficiais em barras laminadas. Faz-se um estudo dos parâmetros que podem influenciar na formação deste tipo de defeito e uma análise da morfologia de trincas. Com relação à composição química, foi alcançada redução na ocorrência de trincas superficiais em barras laminadas através da adição de Ti e redução do teor de Al no aço. Maior temperatura e menor velocidade de lingotamento correspondem à melhor combinação para alcançar redução da ocorrência desse tipo de defeito.
\end{abstract}

Palavras-chave: Trincas; Lingotamento Convencional; Titânio; Alumínio.

\section{STUDY OF EFFECTS OF CHEMICAL COMPOSITION AND INGOT CASTING PARAMETERS ON CRACK OCCURRENCE IN HOT ROLLED BARS}

\section{Abstract}

The objective of this work is to study the effect of chemical composition and ingot casting parameters on the occurrence of surface cracks in rolled bars. It is made a study of the parameters that can influence the formation of this type of defect and an analysis of the morphology of cracks. With respect to the chemical composition, reduction in the occurrence of surface cracks in rolled bars was achieved by the addition of Ti and reduction of Al content in steel. Higher temperature and lower casting speed correspond to the best combination to achieve reduction of the occurrence of this type of defect.

Keywords: Cracks; Ingot Casting; Titanium; Aluminum

Eng. de Materiais, Bacharel, Assessora Técnica, Aciaria, Gerdau, Pindamonhangaba, SP, Brasil. 


\section{INTRODUÇÃO}

O objetivo do presente trabalho é avaliar o efeito de parâmetros de processo, como a composição química, velocidade e temperatura do aço durante o lingotamento, de modo a evitar a formação de trincas que podem aflorar para a superfície durante o processo de laminação à quente.

Para tal, foi empregada a metodologia Seis Sigma utilizando o ciclo PDCA para apoiar a identificação do problema, a análise do fenômeno com auxílio de métodos estatísticos, a elaboração e execução de experimentos e a verificação dos resultados obtidos.

Trincas de painel ocorrem em aços baixo e médio carbono; altamente afetadas pelo tratamento térmico do lingote, sempre associadas a aços tratados com Al. Este tipo de defeito se caracteriza por uma ou mais trincas irregulares e intergranulares que são longitudinais e crescem pelos contornos de grão austeníticos. O problema ocorre principalmente pela combinação de três fatores principais: geração de defeitos em temperaturas intermediárias com ductilidade reduzida $\left(600\right.$ a $\left.900^{\circ} \mathrm{C}\right)$; presença de precipitados fragilizantes de nitreto de Al e geração de tensões devido a contração térmica e transformação de fase. [1]

Trincas se iniciam no contorno de grão enfraquecido sob aplicação de tensões. Durante a solidificação do aço, ocorre a precipitação de nitreto de Al nos contornos de grãos austeníticos. A zona de baixa taxa de deformação e fragilização na austenita envolve nucleação, crescimento e coalescência de vazios no contorno de grão. [2]

Os defeitos apresentam vários formatos através das escalas macro e microscópicas. A fratura dúctil envolve nucleação, crescimento e coalescência de vazios em uma matriz de aço deformada plasticamente, conforme mostra a Figura 1. Essa fratura pode também ser acelerada pela presença de inclusões de segunda fase (inclusões não-metálicas), dependendo de seu agrupamento ou espaçamento. Locais potenciais para a formação de defeitos durante deformação à quente, são geralmente localizados:

- Dentro dos grãos austeníticos (fratura transgranular)

- Nos contornos de grão austeníticos

- Nas interfaces de segunda fase da matriz

- Na segunda fase (inclusões) [3]

Figura 1. Mecanismos de micro-fratura
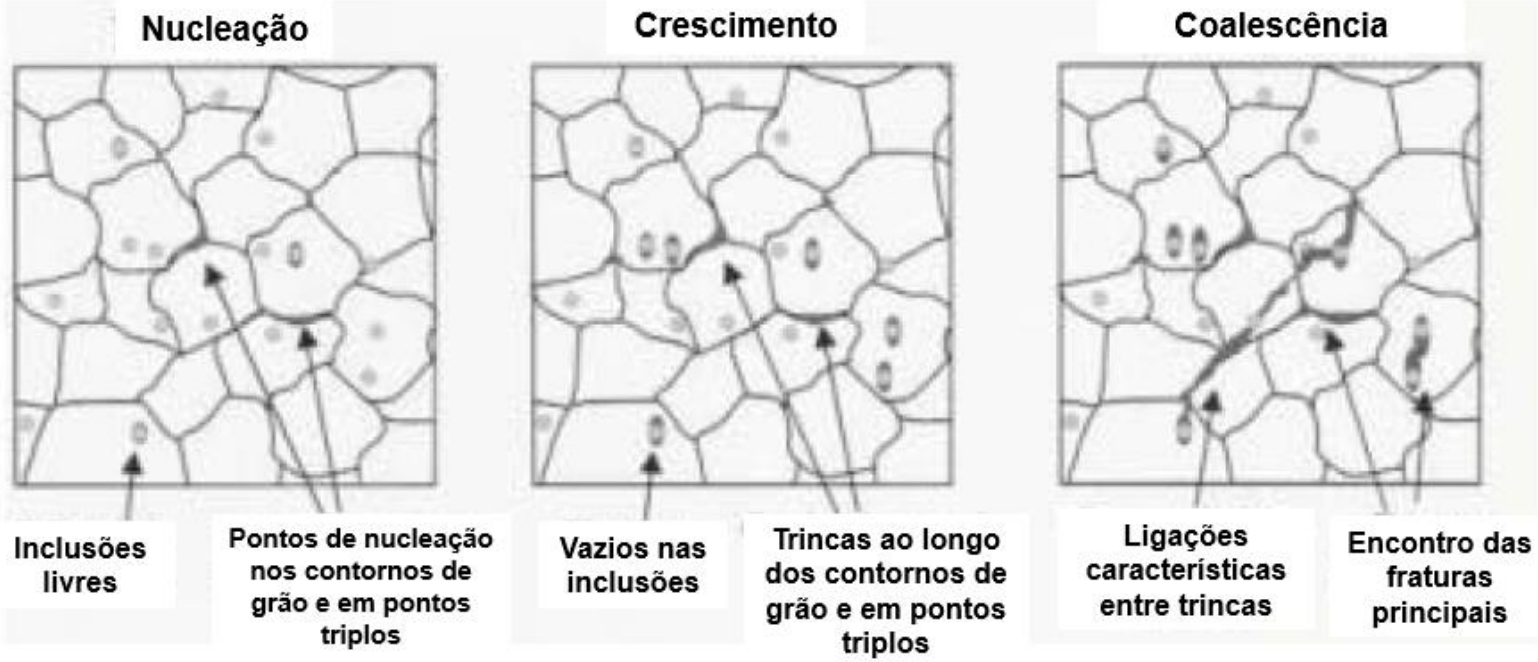
Em geral, a ductilidade dos aços a elevadas temperaturas é excelente. Entretanto, há duas regiões distintas nas quais há queda acentuada de ductilidade.

A primeira zona ocorre a elevadas temperaturas, a aproximadamente $50^{\circ} \mathrm{C}$ da $T$ solidus e a ductilidade nesta zona é zero. Para temperaturas acima de $1300^{\circ} \mathrm{C}$, qualquer tensão aplicada ao aço nesta região irá propagar trincas através da frente de solidificação entre as dendritas. A superfície de fratura nesse caso tem forma arredondada.

A segunda zona, conhecida como zona de temperatura intermediária, vai desde $T$ $>1200^{\circ} \mathrm{C}$ a $\mathrm{T}<600^{\circ} \mathrm{C}$. A concentração de tensão na rede de ferrita circundada por austenita ou perlita a $\mathrm{T}$ menores, é responsável pela redução da ductilidade nesta zona. A fratura que ocorre é transgranular, com dimples e alguns precipitados maiores, indicando que a fratura se inicia em inclusões isoladas dispersas na matriz. A superfície de fratura exibe precipitados de vários tipos: sulfetos (MnS, FeS e AIS); óxidos ( $\mathrm{MnO}$, FeO e AlO) e nitretos (AIN ou NbN). [2]

A fragilização não é possível sem a presença de alguns precipitados de elementos residuais. O Al é um dos elementos mais influentes, pois a precipitação do nitreto de Al ocorre preferencialmente nos contornos de grão austeníticos. Um aumento no teor de Al na faixa de 0,02 a 0,06 causa queda na ductilidade a quente, principalmente abaixo de $900^{\circ} \mathrm{C}$ e também pode agravar o efeito do $\mathrm{Nb}(\mathrm{C}, \mathrm{N})$ precipitado, tornando os precipitados mais finos e concentrados nos contornos de grão.

Segundo a literatura, um aumento no teor de Nb também pode causar queda na ductilidade em alguns casos. Em aços contendo $\mathrm{Al}$ e $\mathrm{Nb}$, os precipitados de $\mathrm{Nb}(\mathrm{C}, \mathrm{N})$ predominam a altas temperaturas, enquanto o AIN é associado a temperaturas mais baixas $\left(700-900^{\circ} \mathrm{C}\right)$. Comportamento semelhante ocorre quando o aço contém $\mathrm{B}$, pois ocorre formação de BN pelo mesmo mecanismo. [1]

$\mathrm{O} V$ é um microligante e formador de nitreto. Não é tão deletério à dutilidade e pode até ser benéfico, podendo evitar a precipitação de AIN a baixas temperaturas.

$\mathrm{O}$ Ti é inquestionavelmente benéfico para reduzir o problema da dutilidade. Previne a formação do AIN, combinando-se com o $\mathrm{N}$ disponível e precipitando TiN mais compacto e menos nocivo, distribuído ao longo da matriz. Precipita a elevadas temperaturas, deixando menos $\mathrm{N}$ disponível para formar precipitados nocivos.

Valores elevados de AIN aumentam a quantidade de defeitos superficiais. Em aços utilizados para perfuração, o Al é utilizado em combinação ao $\mathrm{N}$, para promover refino de grão durante a solidificação. Trincas longitudinais e transversais de diferentes severidades podem ocorrer durante a laminação se a precipitação do AIN não for controlada. [3]

Sulfetos são nocivos em toda faixa de ductilidade reduzida; aumentando o teor de S, reduz-se a ductilidade. O mecanismo predominante para fragilização do aço a elevadas taxas de deformação envolve precipitados de Fe e Mn. O resfriamento lento, permite a difusão lenta do Mn e a formação de precipitados de MnS inofensivos dentro dos grãos, que reduz a formação de FeS no contorno de grão; o que explica o efeito benéfico da elevada relação $\mathrm{Mn} / \mathrm{S}$ ou do baixo teor de $\mathrm{S}$. [1]

Diante deste contexto, as ações propostas para evitar a formação de trincas são:

- Alterar composição química do aço para prevenir a formação de precipitados de nitretos deletérios, diminuindo a adição de formadores de nitreto ( $\mathrm{Al}, \mathrm{Nb}, \mathrm{B}$ e $\mathrm{N})$

- Adicionar Ti para aumentar a ductilidade pela formação de precipitados inofensivos (TiN);

- Diminuir os níveis de S e O ou adicionar Ca ou Mn para reduzir a fragilização por sulfeto);

- Evitar tensão (ou deformação) do aço quando em região de baixa ductilidade; 
- Estripar o lingote do molde rapidamente, mantendo-o aquecido durante o transporte e reaquecer rápido, prevenindo que a superfície caia na faixa de temperatura de baixa ductilidade;

- Baixar teor de N no aço pela inertização do jato com Argônio;

- Evitar track times muito longos;

- Fazer resfriamento lento sem deixar que os lingotes encostem uns nos outros ou fiquem muito próximos, deitando uma das faces em vermiculita (leito isolante).

Muitos outros estudos reforçam a necessidade de se evitar a tensão do aço quando este se encontra em temperaturas de baixa ductilidade. Outro fator importante é realizar o resfriamento lento evitando o contato de um lingote com o outro e destes com o chão, de modo que as faces se resfriem de maneira homogênea, evitando tensões térmicas.

Ao tomar estes cuidados com os fatores térmicos e evitar a formação de nitretos nocivos, obtêm-se significativa redução na ocorrência de trincas em barras laminadas de aços médio e baixo carbono.

\section{MATERIAIS E MÉTODOS}

Com o intuito de analisar a influência da variação dos parâmetros: teor de $\mathrm{Al}$ e Ti, velocidade e temperatura do aço durante o lingotamento para a ocorrência de trincas superficiais em produtos laminados, foram realizados experimentos fatoriais de modo a obter correlações entre os níveis desses fatores e a ocorrência de trinca superficial.

No lingotamento convencional indireto, o aço já com composição química ajustada é vazado de uma panela para mestras ou funis que se conectam a canais de distribuição refratários e proporcionam o enchimento dos moldes ou lingoteiras. Na Figura 2, vemos um sistema padrão de lingotamento convencional indireto.

O controle de velocidade de lingotamento é feito por meio de um painel eletrônico que mostra o valor da velocidade, controlada por uma botoeira que fica nas mãos do operador durante todo o processo.

Figura 2 - Sistema de lingotamento indireto.

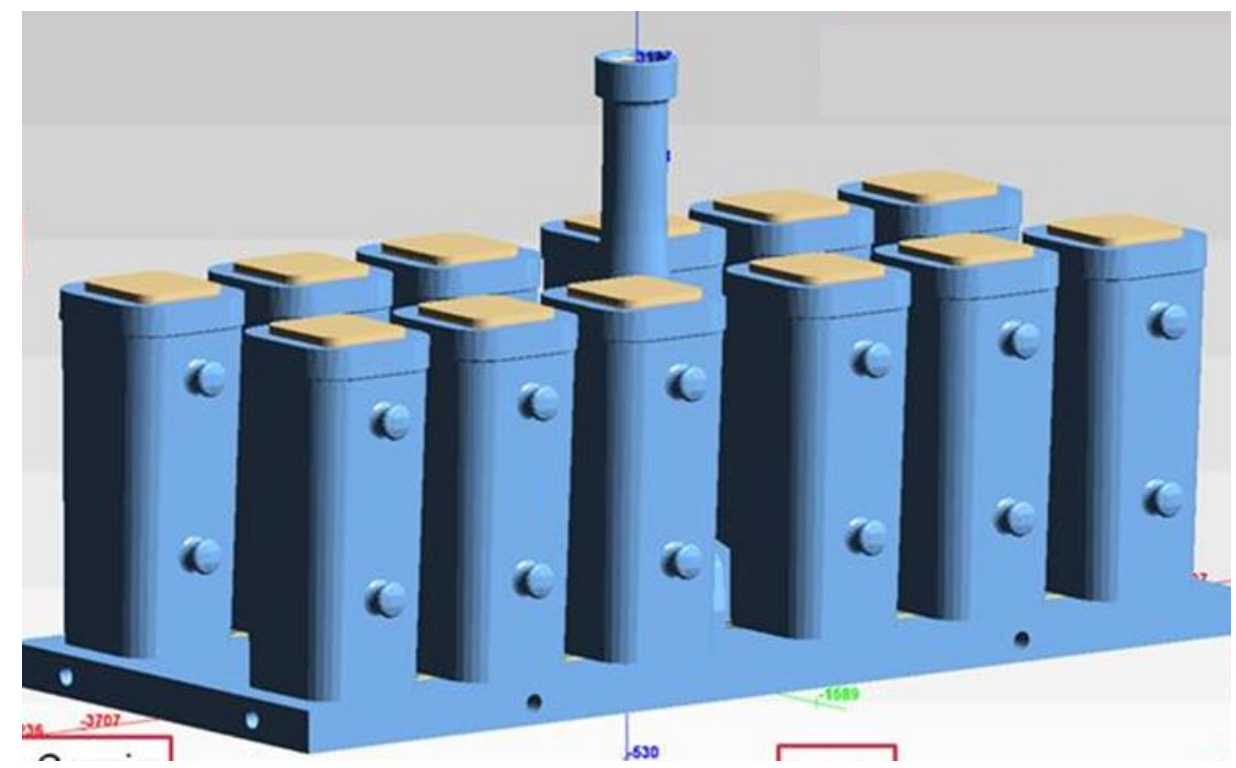




\subsection{Efeito dos teores de Ti e Al no refugo por trinca superficial}

O aço SAE 1045 foi o tipo de aço escolhido para a realização de um experimento fatorial (DOE - Design of Experiments) que avaliou o refugo por trincas de corridas (bateladas de produção) com teores altos e baixos de $\mathrm{Ti}$ e Al, buscando a melhor relação. A inspeção das barras laminadas é realizada através do método de partículas magnéticas. Em seguida, o material passa por inspeção visual para caracterização dos defeitos e definição de liberação ou sucateamento das peças, após avaliação do inspetor. Dessa forma, é definido o refugo ou liberação do material para o cliente. A composição química do aço SAE 1045 é mostrada na Tabela 1.

Tabela 1 - Composição química do aço SAE 1045 estudado.

\begin{tabular}{|c|c|c|c|c|c|}
\hline Elementos & $\mathbf{C}$ & $\mathbf{M n}$ & $\mathbf{A l}$ & $\mathbf{T i}$ & $\mathbf{N}(\mathbf{p p m})$ \\
\hline \% em peso & $0,43-$ & $0,60-$ & $0,004-$ & $0,001-$ & $0,005-$ \\
& 0,50 & 0,90 & 0,04 & 0,03 & 0,013 \\
\hline
\end{tabular}

Para a realização das corridas do experimento, considerou-se um teor de Al "baixo" como sendo de 0,004-0,008 e "alto" de 0,01-0,04. O teor de Ti considerado "baixo" foi definido na faixa de $0,001-0,005$ e "alto" de $0,01-0,03$. O experimento foi realizado com dois fatores e 2 réplicas, o que resultou em um montante de 8 corridas realizadas $\left[\left(2^{2}\right) \times 2\right]$. Utilizou-se nas 8 corridas o mesmo tamanho de lingote produzido. Os demais parâmetros de processo foram mantidos os mesmos para todas as corridas nas etapas de fusão, refino e lingotamento. Na etapa do refino, a adição de ligas foi realizada por meio de injeção de fios ou por silos de ligas com adição controlada.

\subsection{Influência da velocidade e da temperatura no lingotamento}

O aço SAE 1548 foi o tipo de aço escolhido para a realização de um experimento fatorial considerando dois diferentes níveis de velocidade e temperatura de lingotamento.

As velocidades de lingotamento foram previamente definidas com base em simulações realizadas no software MagmaSoft. Os limites foram definidos com base na maior e a menor vazão admissíveis para o modelo de lingoteira utilizado, visando evitar a exposição do aço líquido na superfície do molde.

Desse modo, chegou-se aos valores 1,6 t/min como sendo o mínimo aceitável e 2,6 t/min como sendo o máximo aceitável.

A temperatura de lingotamento considerada "alta" foi $1554^{\circ} \mathrm{C}$ e a considerada "baixa", de $1542^{\circ} \mathrm{C}$. Os diferentes níveis de temperatura puderam ser obtidos em um mesmo processo de lingotamento em diferentes canais de alimentação (mestras). 


\section{RESULTADOS E DISCUSSÃO}

\subsection{Efeito dos teores de Ti e Al na ocorrência de trinca superficial}

O experimento fatorial para a composição química do aço SAE 1045, mostra que as condições de processo que apresentam os menores refugos por trinca são: baixo teor de Al e alto teor de Ti. A Tabela 2 mostra os parâmetros utilizados, os teores (em ppm) de Ti e Al obtidos na composição química final do aço e o percentual de barras com ocorrência de trincas. Para as 8 corridas do experimento, não foram alterados os teores de $\mathrm{N}$ do aço, mantendo-se o limite mínimo de 0,005 e o limite máximo de 0,013, de modo que os teores de $\mathrm{N}$ disponíveis para a formação dos nitretos se mantivessem próximos em todos os testes.

Tabela 2. Parâmetros e resultados obtidos no Experimento Fatorial para teores de Ti e Al

\begin{tabular}{|l|c|c|c|}
\hline \multicolumn{1}{|c|}{ Condição } & $\begin{array}{c}\text { Al (\% em } \\
\text { peso) }\end{array}$ & $\begin{array}{c}\text { Ti (\% em } \\
\text { peso) }\end{array}$ & $\begin{array}{c}\text { \% de } \\
\text { barras com } \\
\text { ocorrência } \\
\text { de trincas }\end{array}$ \\
\hline Alto Al, Baixo Ti & $\begin{array}{c}0,01- \\
0,04\end{array}$ & $\begin{array}{c}0,001- \\
0,005\end{array}$ & 2,22 \\
\hline Alto Al, Alto Ti & $\begin{array}{c}0,01- \\
0,04\end{array}$ & $\begin{array}{c}0,01- \\
0,03\end{array}$ & 0,64 \\
\hline Baixo Al, Baixo Ti & $\begin{array}{c}0,004- \\
0,008\end{array}$ & $\begin{array}{c}0,001- \\
0,005\end{array}$ & 0,49 \\
\hline Baixo Al, Alto Ti & $\begin{array}{c}0,004- \\
0,008\end{array}$ & $\begin{array}{c}0,01- \\
0,03\end{array}$ & 0,00 \\
\hline
\end{tabular}

O Gráfico 1 (a) e (b), obtido utilizando-se o software estatístico Minitab, mostra as análises dos efeitos principais teor de Al e teor de Ti na média de ocorrência de trinca superficial em barras laminadas.

Gráfico 1. Comparação dos efeitos principais da composição química do aço SAE 1045 (a) teor de Al e (b) teor de Ti com relação à ocorrência de trinca superficial em barras laminadas.

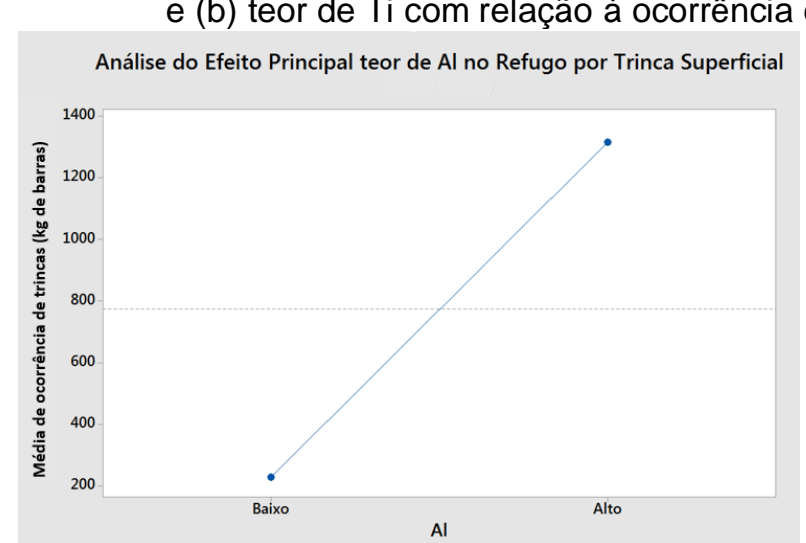

(a)

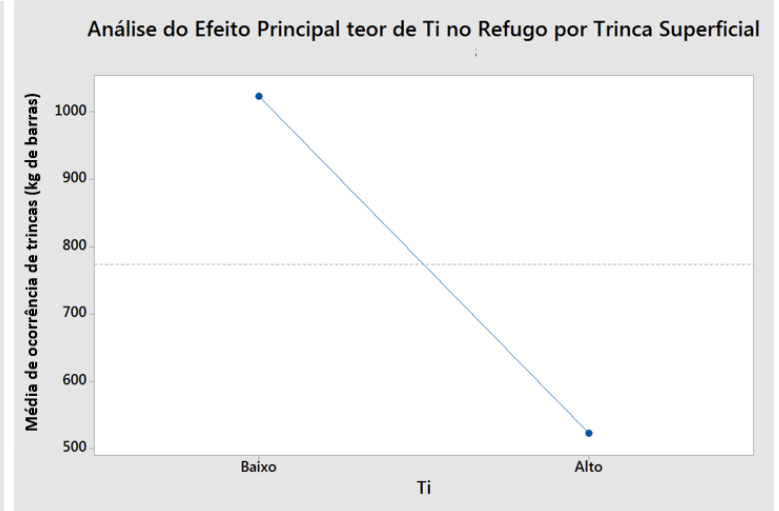

(b)

A composição química dos aços tem papel importante na fragilização destes a temperaturas acima de $600^{\circ} \mathrm{C}$. O resultado do experimento fatorial reforça o que foi 
dito na literatura sobre o benefício da adição de Ti para reduzir o problema da baixa ductilidade em determinadas faixas de temperatura.

Como visto na literatura, o efeito do titânio está associado à formação preferencial de TiN em temperaturas elevadas, prevenindo a formação de AIN (deletério). O TiN precipita de maneira uniforme na matriz austenítica e sua precipitação é menos prejudicial do que a do AIN. O titânio melhora a ductilidade à quente quando temos uma razão Ti/N é maior do que 3,4. [4]

Na Figura 3 podemos observar a microestrutura de uma trinca no aço SAE 1045 utilizado para o teste, com forte descarbonetação, o que indica que possivelmente a trinca se originou na estrutura bruta de solidificação, ou seja, no lingote e foi intensificada durante a laminação. A descarbonetação indica a exposição a atmosferas oxidantes em elevadas temperaturas. É dependente de tempo e temperatura por causa da difusão do carbono. [5]

Como previamente à laminação o lingote é reaquecido e permanece no forno por determinado tempo, temos essas duas variáveis para a difusão ocorrer.

Figura 3. Microestrutura de trinca no aço SAE 1045 estudado.

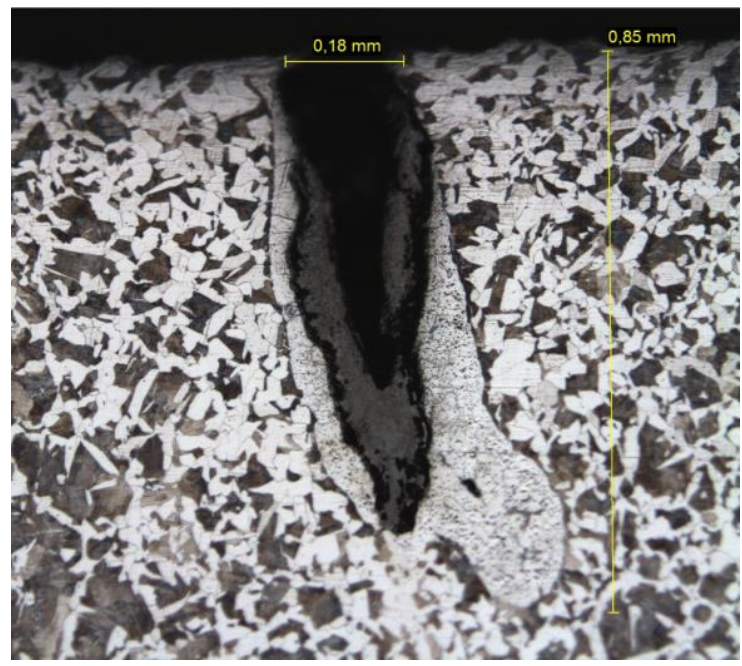

Não foi realizada alteração no teor de $\mathrm{N}$ dos aços estudados, mas sabemos que, de acordo com a literatura sobre o tema, se reduzirmos o teor desse elemento no aço líquido, é menor a sua disponibilidade para reagir com o Al para a formação de nitretos deletérios.

\subsection{Efeito da temperatura e velocidade de lingotamento na ocorrência de trinca superficial}

O experimento fatorial para os parâmetros velocidade e temperatura de lingotamento, mostra que as melhores condições de processo para reduzir a ocorrência de trincas superficiais são temperatura alta e velocidade baixa. A Tabela 3, mostra os dados das corridas testadas com os parâmetros utilizados e ocorrência percentual de trincas. $O$ Gráfico 2, mostra a interação entre os fatores temperatura e velocidade e mostra que 
a melhor condição para reduzir a ocorrência de trica superficial é temperatura alta e baixa velocidade de lingotamento.

Tabela 3. Parâmetros e resultados obtidos para temperatura e velocidade de lingotamento.

\begin{tabular}{|l|c|c|c|}
\hline \multicolumn{1}{|c|}{ Condição } & $\begin{array}{c}\text { Temperatura } \\
(\mathbf{T}){ }^{\circ} \mathbf{C}\end{array}$ & $\begin{array}{c}\text { Velocidade } \\
\text { (V) } \mathbf{t} / \text { min }\end{array}$ & $\begin{array}{c}\text { \% de } \\
\text { barras } \\
\text { com } \\
\text { ocorrência } \\
\text { de trincas }\end{array}$ \\
\hline Alta T, Baixa V & 1554 & 1,6 & 0,36 \\
\hline Alta T, Alta V & 1554 & 2,6 & 0,71 \\
\hline Baixa T, Baixa V & 1542 & 1,6 & 0,62 \\
\hline Baixa T, Alta V & 1542 & 2,6 & 0,74 \\
\hline
\end{tabular}

Gráfico 2. Interação entre os parâmetros velocidade e temperatura de lingotamento na ocorrência de trincas.

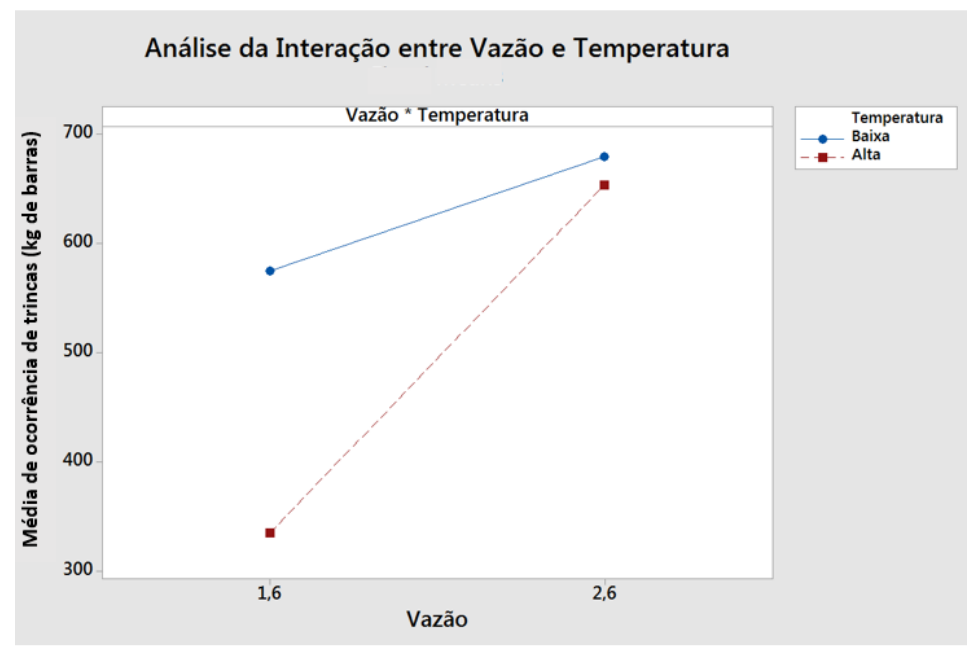

Trincas superficiais podem ser formadas devido à fricção entre a parede do molde e a superfície do lingote. Podemos associar uma menor velocidade de lingotamento a um fluxo com menor turbulência e redução da fricção entre a parede e o aço em início de solidificação no interior da lingoteira. Para o teste realizado, a maior temperatura do aço no lingotamento também fornece a melhor condição para redução de refugo por trinca.

\section{CONCLUSÃo}

Neste trabalho foram analisados os efeitos dos teores de $\mathrm{Al} \mathrm{e} \mathrm{Ti,} \mathrm{velocidade} \mathrm{e}$ temperatura de lingotamento na ocorrência de trincas superficiais em barras laminadas. Com base nos resultados obtidos, tiramos as seguintes conclusões: 
- Considerando os teores de Al e Ti no aço SAE 1045, verificamos que menores teores de Al e maiores teores de Ti proporcionam menor ocorrência de trincas superficiais nas barras laminadas.

- A metalografia das amostras do material do teste mostra que para o aço SAE 1045 das corridas estudadas, as trincas podem ter origem na aciaria devido à sua descarbonetação simétrica em torno do defeito.

- Para o aço SAE 1548, as condições do processo de lingotamento nas quais é menor a ocorrência de trincas são: maior temperatura do aço e menor velocidade de lingotamento.

\section{Agradecimentos}

Agradeço a Gerdau Aços Especiais Pindamonhangaba pela disponibilização de recursos para a execução deste trabalho.

\section{REFERÊNCIAS}

1 Thomas BG, Brimacombe JK, Samarasekera IV. The Formation of Panel Cracks in Steel Ingots: A State-of-the-Art Review, Part 1. ISS Transactions. 1986;(7):7-20.

2 Thomas BG, Brimacombe JK, Samarasekera IV. The Formation of Panel Cracks in Steel Ingots: A State-of-the-Art Review, Part 2. ISS Transactions.1986;(7):21-29.

3 Farrugia D, Husain Z, Santisteban V, Llanos J, Bianchi J, Vescovo P, Pera J, Rodriguez-lbabe J, Revilla C, Fredriksson J, Demurger J, Forestier R, Kieber B. PACROLP: the prediction and avoidance of cracking in long product hot rolling. Research Found for Coal and Steel. 2009 (1): 16-21

4 Pigatti GM, Nicolin VAF, Grillo FF. Avaliação do Impacto do titânio e carbono equivalente na ductilidade a quente dos aços médio carbono. R. Escola de Minas, Ouro Preto, 66 (4): 455-460.

5 Castilhos E. Contribuição para a caracterização de defeitos superficiais em barras laminadas. Trabalho de diplomação. Universidade Federal do Rio Grande do Sul. 2008;(1):4-5. 